\title{
TEMPO E HISTÓRIA: BLANQUI NA LEITURA DE BENJAMIN*
}

\author{
History and time: Benjamin's reading Blanqui \\ Anita Helena Schlesener**
}

\begin{abstract}
RESUMO
Este artigo apresenta algumas considerações sobre as noções de Tempo e História em escritos de Walter Benjamin produzidos a partir de sua leitura de Blanqui, cotejada com a de Nietzsche. A categoria empregada por Benjamin para analisar a história social é a de tempo como eterno retorno. Tal leitura permitiu a Benjamin criticar os pressupostos do marxismo implícitos na idéia de revolução.
\end{abstract}

Palavras-chave: temporalidade, história, Blanqui.

\begin{abstract}
This article presents some ideas about the notions of Time and History in Walter Benjamin's text, generated from his reading of Blanqui and Nietzsche. The category employed by Benjamin to analyze the social history is the time as eternal return. This reading permited to review the presupposed of marxism implicit in revolution's idea.
\end{abstract}

Key-words: temporality, history, Blanqui.

de 2002 .

* Texto apresentado na ANPOF - Associação Nacional de Professores de Filosofia - em outubro

** Professora do Departamento de Filosofia da UFPR, Doutora em História. 


\section{Introdução}

Tudo na terra imerge no abismo, nas chamas renovadoras, no fluir monótono da ampulheta que eternamente inverte a si própria e se esvazia. É o novo sempre antigo e o antigo sempre novo.

Parte-se da referência de Benjamin à noção de tempo que Blanqui apresenta em seu livro L'éternité par les astres e que remete tanto à temporalidade presente na poesia de Baudelaire quanto prenuncia a noção nietzscheana de eterno retorno. As idéias de Blanqui, cuja leitura foi mediada pelo livro de Gustave Geffroy (L'enfermé - 1897) sobre a vida do grande revolucionário, perpassam os escritos de Benjamin sobre o tempo e a história.

Louis Auguste Blanqui seguiu a tradição conspiratória de Babeuf e dedicou sua vida a organizar grupos centralizados para incentivar insurreições contra o poder capitalista. Revolucionário, rebelde, passou mais de 35 anos na prisão, mas nunca abriu mão de seu objetivo. Marx admirava a coragem de Blanqui, a quem denominava alquimista da revolução e, a propósito do movimento malogrado de junho, viu nele "o verdadeiro chefe do partido proletário". ${ }^{1}$ Basta lembrar as palavras de Blanqui durante o interrogatório de 1832 quando, preso como participante da Sociedade dos Amigos do Povo, construiu sua defesa atacando os que ele denominava inimigos da liberdade e da felicidade do povo:

- O presidente: Dizei-me o vosso nome, idade, local de nascimento e residência. - Blanqui: Louis-Augiste Blanqui, vinte e seis anos de idade, nascido em Niza, com residência em Paris, rua de Monteruil, n. 96, bairro Saint-Antoine. - O presidente: Qual é a vossa profissão? - Blanqui: Proletário. - O presidente: Isso não é profissão. - Blanqui: Por que não é profissão? Mas é exatamente a profissão de trinta milhões de franceses, que vivem do trabalho e se encontram privados de direitos. - O presidente: Bem, está certo...2

1 Apud BENJAMIN, W., Gesammelte Schriften I, 1, 2 und 3 (Abhandlungen). Frankfurt: a.M.: Suhrkamp Verlag, 1997. p. 1157. (Nas notas seguintes esta obra constará com a sigla GS.)

2 VV. AA. O socialismo antes de Marx. Amadora, Portugal : Fronteira, 1976, p. 55. Também citado por Benjamin. 
A interpretação de Marx sobre o movimento de junho revelava a ambigüidade da atividade conspirativa de Blanqui, ora apresentado como um líder pronto a um golpe de Estado, ora como um típico representante do habit noir, figura odiada no meio dos conspiradores profissionais. Blanqui atuava, na opinião de Marx, no sentido de "apressar o processo revolucionário em curso, levá-lo artificialmente à crise, mesmo sem haver as condições concretas para uma revolução". A admiração de Benjamin se expressa na comparação que ele faz do líder revolucionário com Lenin, o líder da revolução russa. ${ }^{3}$ Blanqui produziu um pensamento tão radical que talvez não coubesse no corpo teórico que predominou no decurso da história política do proletariado, de tal modo que precisou ser anulado e esquecido.

Estas características críticas também marcaram a poesia de Baudelaire. Entre as semelhanças, Benjamin acentua a austeridade misteriosa do líder revolucionário e o tom enigmático da alegoria do poeta. Mas o que se tornou o ponto de relação entre os dois autores no trabalho de Benjamin foi o conceito de tempo, caminho aberto para a crítica histórica.

Blanqui buscava na experiência cósmica vivenciada pelos antigos os elementos para refletir sobre a grande antinomia que se produziu na história da modernidade, a saber, a de uma realidade da repetição permeada pelo desejo de eternidade. A partir de uma reflexão sobre os movimentos astrais, que estendeu para a experiência existencial e histórica, Blanqui realizou o que Benjamin denomina "o mais terrível ato de acusação contra uma sociedade" que projeta sua imagem no cosmo. ${ }^{4}$

O livro de Blanqui desvela o mito do tempo contínuo, a constelação de fantasmagorias que compunham o quadro mistificador do século XIX, principalmente na idéia de progresso: "Blanqui queria esboçar uma imagem do progresso. E a descobriu como imagem enfeitiçada da própria história: como antigüidade sem memória na veste do mais moderno", isto é, repetição infinita do mesmo. ${ }^{5}$ A mesma monotonia, que é a medida de todo o universo, reproduzse na história moderna que, como o eterno trabalho de Sísifo, se concretiza como repetição da dominação, da repressão, do sofrimento e do fracasso das tentativas revolucionárias.

A leitura benjaminiana de Blanqui se realizou em dois caminhos que se entrelaçam: mostrou que a contribuição de Blanqui deixa antever a radicalidade

3 BENJAMIN, GS., I-3, p. 1157. Edição brasileira, BENJAMIN, W. A Paris do segundo império em Baudelaire. In: Sociologia. São Paulo : Ática, 1985, p. 49.

4 BENJAMIN, W. Briefe II. Carta de 06 de janeiro de 1938, p. 741-2.

5 BENJAMIN, GS., I-3, p. 1153 (tradução nossa). 
e a força crítica do materialismo histórico e avançou no sentido de libertar o pensamento de Blanqui da interpretação puramente política, que fazia dele um rebelde, cuja contribuição teórica se restringia à formulação dos pressupostos do coup de main, para apresentá-lo como intelectual que desvelou o mito implícito na forma temporal da sociedade moderna e realizou uma das críticas mais radicais à sociedade burguesa.

Não obstante isso, Blanqui desafiou todos os poderes instituídos e persistiu em organizar a insurreição. A clara consciência da mistificação da realidade, conforme Benjamin, se revela no caráter desesperado de sua ação política, no seu desinteresse pelos fundamentos teóricos do socialismo e na profunda desconfiança na expectativa socialista no futuro, substituída pelo esforço em mergulhar no passado. ${ }^{6} \mathrm{Na}$ combinação paradoxal de resignação e revolta que permeava sua ação, Blanqui reformulava o próprio conceito de revolução que, no contexto de uma visão de mundo cosmológica, assumia o sentido de ruptura do tempo, na necessidade de superar a "vertigem do abismo" gerada no âmbito da sociedade moderna.

A partir do último fragmento de Rua de mão única, que se denomina $A$ caminho do Planetário, percebe-se que esse tema já fazia parte das reflexões de Benjamin em 1927. Benjamin acentuava ali a radical diferença entre os antigos e os modernos na sua experiência do espaço e do tempo dizendo que o "trato dos antigos com o cosmos cumpria-se na embriaguez", na vida comunitária: "É embriaguez, decerto, a experiência na qual nos asseguramos unicamente do mais próximo e do mais distante, e nunca de um sem o outro." ${ }^{7}$ Tal relação, perdida na experiência moderna, caracteriza também a perda da aura, perda que se traduz na proximidade sem distância, isto é, no particular (o objeto e suas funções imediatas e utilitárias) sem o universal (a dimensão histórica no elo com a tradição). A aura se insere num contexto de sacralidade que foi destruído no processo de racionalização.

Na cultura antiga o termo embriaguez se remetia à tradição dionisíaca em que convergiam o erótico e o político, cuja origem se encontrava no cotidiano dos que estavam à margem da orden social reconhecida e sacralizada.

O mundo dionisíaco era a expressão do movimento cósmico liberador, da poderosa força vital que emana das coisas e que integra o homem à natureza. Trata-se de uma força instintiva não domesticada, avassaladora, incontrolável e evanescente, que escapa ao controle meticuloso da razão e envolve

6 Ibid., p. 1154.

7 BENJAMIN, W., A caminho do planetário. In: Obras Escolhidas II - rua de mão única. São Paulo: Brasiliense, 1987, p. 68. 
principalmente os que se encontram fora da esfera do poder, constituindo-se, na maioria das vezes, na força propulsora de sua ação: é na esfera popular que erótico e político se combinam na insurreição e na conspiração política, objetivos da atuação de Blanqui.

Na modernidade, esta força vital é controlada ou sufocada: a razão formalista, característica do saber moderno, tornou-se o meio de dominação da natureza e de submissão da vida humana aos imperativos do modo de produção. $\mathrm{O}$ mundo dos sentidos, que se identifica com o mundo natural e que permitia a conciliação do homem com a natureza no mundo antigo, agora é domesticado, submetido, para cumprir os objetivos do mundo do trabalho. $\mathrm{O}$ "ameaçador descaminho dos modernos é considerar a experiência (do comunicar-se em embriaguez com o cosmos) como irrelevante, como descartável" e relegá-la ao indivíduo isolado. ${ }^{8} \mathrm{O}$ rompimento dos elos com o passado se manifesta no individualismo, no isolamento do homem moderno reduzido a uma mercadoria, na perda do olhar, que se traduz em perda da capacidade de contemplação (contemplar tornou-se "devaneio místico").

A crença na evolução das técnicas e no progresso contínuo e irreversível, bem como a sua concretização no modo de produção capitalista estão na base dessa mudança: Benjamin esclarece que na sociedade moderna “a 'imparcialidade', o 'olhar livre' são mentiras (...) o olhar mais essencial hoje, o olhar mercantil que penetra no coração das coisas, chama-se reclame", que "desmantela o livre espaço de jogo da contemplação" porque ocorre em condições que impossibilitam o distanciamento. Era a relação entre próximo e distante, própria da experiência antiga, que integrava a história individual com a história coletiva, o homem ao cosmos. A "vinculação ótica ao universo", ${ }^{10}$ própria da modernidade, se produz com o filtro da ciência e da técnica: a partir dela, o astrônomo determina a posição dos astros e sua atividade se separa radicalmente da ação do astrólogo que, desenvolvendo a percepção das semelhanças, lê o futuro contido nas estrelas. Apesar de toda a precisão de seus instrumentos de observação, o astrônomo nunca conseguirá igual resultado. ${ }^{11}$

As correspondências mágicas, próprias do olhar dos povos antigos, se perderam no universo do homem moderno. As imagens rápidas, explícitas e

8 Id.

9 BENJAMIN, W. Estas áreas são para alugar. In: Obras Escolhidas II - rua de mão única, p. 54-

55.

10 BENJAMIN, A caminho do planetário, p. 68.

11 BENJAMIN, W. A doutrina das semelhanças. In: Obras Escolhidas - magia e técnica, arte e política. São Paulo: Brasiliense, 1985, p. 110. 
repetidas, que desfilam diante do olhar distraído do passante, calam a imaginação e se confundem com a experiência direta, ocasionando indiferença e insensibilidade, até embotar a capacidade de assimilar e compreender. Olha-se sem ver, porque a visão não depende exclusivamente da presença constante e insistente da imagem: a visão se produz pela percepção do distante que transparece nas dobras do aparente, pelas significações que se acumulam sob o imediatamente dado e que pedem desvelamento. Ver se caracteriza por descobrir, além das aparências, os significados produzidos ao longo da história e guardados na memória.

O olhar do homem moderno é um olhar vazio, que revela a ausência de quem olha, transformado em objeto (do sistema de produção, da mídia, do consumo). Vazio, tanto no sentido de perda da abrangência do olhar ${ }^{12}$ quanto do significado do que a imagem apresenta. Reduzido à visão imediata, o homem moderno sucumbe ao imediatamente dado: para ele, "é o dinheiro que aproxima dele as coisas, que estabelece o contato conclusivo com elas". ${ }^{13}$

Essa transformação da experiência, concomitante à mudança de percepção do mundo pelo homem moderno, teve como correlato a secularização do tempo em espaço. No fundo, a questão que se coloca é a da dissolução ou dispersão do sujeito num mundo em que imperam as leis de mercado. Se, no âmbito teórico, o sujeito é a base de sustentação do mundo moderno, na prática, as relações mercantis e de trabalho regem a vida cotidiana e confluem na concepção linear da história. A evolução das técnicas e sua aplicação na sociedade industrial é presidida por uma idéia de tempo quantitativo, mecânico, causal, que define a ordem das sucessões. A vivência da temporalidade pelo indivíduo também coincide com o tempo mensurável e repetitivo do trabalho, da vida na fábrica, tempo mecânico que controla a atividade produtiva, ao qual se acrescentou, no decurso da consolidação do sistema, o tempo da vigilância invisível, que faz parte do cotidiano dos grandes centros urbanos e tende a se tornar permanente. A esse tempo matemático, seqüencial, exterior, se acrescenta o tempo vegetativo, de reposição das energias para novas jornadas de trabalho, da existência vazia e injustificada, da perda de identidade, da apatia política.

A grande contribuição de Blanqui, tanto na teoria quanto na prática revolucionária, está em desvelar a forma temporal moderna como prisão infernal e denunciar a fé no progresso, contrapondo a ela a sua revolta e a sua vontade

12 Perdeu-se a visão da paisagem, que se produz da vibração da distância na mais rigorosa ligação com a proximidade. BENJAMIN, W. Guichê de achados e perdidos. In: Obras Escolhidas II - rua de mão única. São Paulo: Brasiliense, 1987, p, 43.

13 BENJAMIN, Estas áreas são para alugar, p. 55. 
resoluta de mudanças. "O insubstituível valor político do ódio de classe consiste exatamente nisso, em nutrir a classe revolucionária com uma saudável indiferença para com as especulações sobre o progresso" e expressar, nesse feito, a revolta humana contra o que alimenta a soberana injustiça. ${ }^{14}$

A posição de Blanqui é expressão do fundamento crítico do materialismo histórico, que se perdeu com a hegemonia da social-democracia alemã. E é precisamente esta postura crítica que mobiliza Benjamin e dá a seu texto a força interpretativa e de confrontação com a tradição oficial do marxismo.

\section{Blanqui no contexto do século XIX: o conceito de eterno retorno}

No fundo, como é melancólica esta eternidade do homem através das estrelas!.

Imagem do abismo, superação do tempo, doença do tempo ou vazio que nos circunda, invencível angústia, a formulação do eterno retorno também perpassa a literatura e pode ser encontrada em Dostoievski, em Os irmãos Karamazov, bem como na grandiosa obra de Proust, principalmente em O tempo redescoberto. Em Leopardi, o universo se apresenta como um deserto de tédio onde se encontra um oásis de horror: a consciência da imobilidade e do vazio. $\mathrm{E}$, sem dúvida, uma das figuras principais foi Baudelaire, em cuja poesia a indagação sobre o tempo e a repetição são recorrentes: o mundo moderno crê cegamente no progresso e se "afunda na rigidez da morte". ${ }^{15} \mathrm{Na}$ filosofia, Schopenhauer abordou o tema na reflexão sobre o teatro em que, na mudança dos dramas e das máscaras, os atores permanecem os mesmos. E Freud redefine a questão no âmbito da relação consciente-inconsciente, construindo as bases do saber científico sobre a temporalidade moderna. A idéia do eterno retorno parece recorrente na produção cultural do século XIX e início do século XX.

14 BENJAMIN, GS., V-I, p. 428.

15 BENJAMIN, W., Parque central. In:____. Sociologia (coletânea). São Paulo: Ática, 1985, p. 145, frag. 34. 
Daí haver uma certa coincidência e mesmo uma impressionante afinidade de pensamento entre Blanqui e Nietzsche, por exemplo, na formulação do conceito da eterna repetição do mesmo. Benjamin acentua que Blanqui lançou uma nova luz sobre a questão da modernidade e "proclamou a idéia do eterno retorno dez anos antes" que Nietzsche em Zaratustra. ${ }^{16}$

$\mathrm{Na}$ verdade, Nietzsche não relacionou suas idéias às de Blanqui, mas as bases das duas teorias cosmológicas são muito semelhantes: Nietzsche não se referiu a elementos, mas a forças constantes no mundo que, embora múltiplas, são finitas. Apenas o fragmento 341, de A Gaia Ciência, parece retomar as palavras de L'éternité par les astres: A “eterna ampulheta da vida será sempre invertida outra vez - e tu com ela, poeirinha da poeira" salienta Nietzsche; "o fluir monótono da ampulheta que eternamente se inverte e eternamente se esvazia. É o novo sempre antigo e o antigo sempre novo", acentuava Blanqui.

Em linhas gerais, Nietzsche afirmou que, num tempo infinito, as duas possibilidades que se colocavam eram: ou um estado de equilíbrio estável ou o eterno retorno do mesmo. Mas as possíveis semelhanças não escondem uma diferença fundamental: a análise de Blanqui não apenas antecede cronologicamente a de Nietzsche, mas se remete a um contexto político diverso. Benjamin alerta para o papel político da doutrina do eterno retorno na obra nietzscheana: "Existe um projeto no qual é Cesar ao invés de Zarathustra o portador da doutrina nietzscheana (...) O fato é significativo: sublinha que Nietzsche pressentia a cumplicidade da própria doutrina com o imperialismo". ${ }^{17}$

A concepção de eterno retorno possibilita compreender a principal forma de reprodução social moderna, que consiste em alimentar-se do novo, assimilando-o ao instituído. A sociedade capitalista precisa renovar-se internamente para preservar as características da produção (exploração do trabalho e expansão do mercado $)^{18} \mathrm{e}$, para tanto, precisa do novo, da criatividade própria da condição humana. Mas o novo é absorvido e assimilado, perdendo-se no tecido da reprodução capitalista. Tem-se uma sociedade que nasceu da ruptura e que colocava o novo como condição de sua existência, agora reduzindo o novo a um mero mecanismo de permanência e sustentação das formas sociais vigentes. A modernidade se mostra como um modo de vida que instaura um tempo mecânico e imperativo, fundado na repetição do trabalho, que se estende e se aprofunda na serialidade da técnica e do tempo implacável do "sempreigual", dissimulado na figura do novo.

16 BENJAMIN, GS. I-3, p. 1152 - 1153.

17 BENJAMIN, W. Paris, capital do século XIX (ed. italiana), Torino: Einaudi, 1986, p. 171. 18 MARX, K. Manifesto do Partido Comunista. Rio de Janeiro: Zahar, 1978, p. 96-97. 
Enquanto forma temporal da sociedade burguesa, a repetição se revela, portanto, como o mito que funda a modernidade, o "tempo do inferno", tempo da repetição do gesto e das ações no mundo do trabalho, que fragmenta nossa experiência e nos exila da tradição. A vivência do tempo moderno, mecânica e abstrata, difere da temporalidade expressa na tradição, nascida do elo comunitário e da experiência construída coletivamente e preservada na memória.

Mas o eterno retorno não se reduz à idéia da repetição: na proposição antinômica que contrapõe realidade e desejo, revela-se a aspiração de mudanças, a necessidade de superar as carências da ordem social instituída e a busca de realização do sonho de liberdade. Conhecer é ainda repetir, mas para transformar: a arte de contar histórias, de narrar com a maior exatidão, porém, com liberdade para interpretar como quiser, característica da narrativa, ${ }^{19}$ ou o aprender por semelhanças e construir o saber do mundo por meio da mímese e do jogo, própria da aprendizagem da criança, são processos que nos inserem na tradição. A "essência do brincar é um 'fazer sempre de novo', transformação da experiência mais comovente em hábito". ${ }^{20}$ A repetição significa, aqui, experiência e criação, o 'novo' que, embora evanescente e fugidio, pode romper o círculo do eterno repetir. ${ }^{21}$

Ao desvelar a temporalidade moderna como vertigem do sempre-igual que se sedimenta no tempo reduzido ao espaço e se oculta sob a falsa aparência do novo (transformado em novidade), Blanqui se aproxima de Baudelaire, para quem o futuro se apresentava apenas como um cortejo de sofrimentos, angústias e injustiças: a caducidade e a morte constituem a nossa irrevogável condição. "As estrelas que Baudelaire exila do seu mundo são exatamente as que em Blanqui se tornam o palco do eterno retorno". ${ }^{22}$

O desencanto com o futuro se manifesta na melancolia heróica, a postura de aniquilamento e resistência, indignação e ódio, ação permeada pelo profundo sentimento de impotência, são pontos de aproximação entre Blanqui e Baudelaire.

19 BENJAMIN, O narrador. In: Obras Escolhidas I, p. 203.

20 BENJAMIN, W. Brinquedos e jogos. In: . Reflexões: a criança, o brinquedo, a educação. São Paulo: Summus, 1984, p. 75.

21 BENJAMIN, GS. I-3, p. 1152.

22 BENJAMIN, Parque Central, frag. 19, p. 135. 
$\mathrm{Na}$ tradição antiga, herói era aquele que demonstrava qualidades excepcionais (coragem, desinteresse, caráter) no desempenho de uma função, a força da alma na ação, a virtude superior na resistência aos obstáculos. Era também aquele que subvertia a ordem cósmica e se revelava como semideus, porque superava os limites humanos. E, ao romper os liames que o ligavam aos deuses e ao mundo, o herói se refugiava no silêncio, na "gelada solidão do próprio eu", "acima da esfera da personalidade que, pela fala, se demarca e se individualiza". Ausente do que lhe é exterior porque diverso (aquém e além) do comunitário, o herói exprime, por meio do silêncio, o "desafio rígido da suprema auto-suficiência". ${ }^{23}$

Heróico significava também erótico, expressão da força vital que integrava o homem ao movimento cósmico liberador que constituía a experiência da embriaguez. Heróico era ainda o acontecimento memorável, resultado da coragem e da paixão impetuosa que se concretizavam na ação ou na tragédia.

A imagem moderna do herói se produz como resistência às repercussões da produção capitalista sobre o homem no cotidiano repetitivo: herói é aquele que resiste a perder-se no anonimato, a reduzir-se a mera mercadoria e procura viver conforme suas paixões e vontade. Tal figura se delineia na obra de Baudelaire, nos personagens que constituem o seu imaginário poético: o herói baudelaireano combate em nome do novo, que ele procura extrair do velho. O novo aparece como "o fim consciente da produção poética" e como questionamento do existente. Porém, o novo contém em si a transitoriedade, a caducidade, como um "estigma que cada um porta em sua realidade", ${ }^{24}$ o que torna paradoxal a busca do poeta e tende a levar ao fracasso qualquer tentativa heróica. Não é a contingência humana que é lamentada, mas sim o que fizeram dela na ordem social burguesa: a repetição no contexto da estrutura capitalista torna tudo sem sentido. É o que o poeta identifica como a rigidez da morte.

A consciência dessa realidade se traduz como revolta ou como melancolia: a primeira se opõe à resignação, que imprime um tom de desespero à ação; a segunda, resulta da consciência da falta, da ausência do que corresponde ao sonhado e ao desejado, expressando-se no sentimento de tristeza ou na forma da meditação. Blanqui, na singularidade de sua experiência, se apresentava como a figura típica do herói moderno, que não exitava em se indignar e se revoltar, mesmo considerando-se já vencido. Em sua revolta fadada ao constante fracasso, Blanqui retratava uma imagem da classe revolucioná-

23 BENJAMIN, W. Origem do drama barroco alemão. São Paulo: Brasiliense, 1984, p. 131. 24 BENJAMIN, GS. I, 3, p. 1152. 
ria cuja força destruidora não conseguia se impor às artimanhas do jogo reacionário. Já Baudelaire "moldou a sua imagem de artista segundo a imagem do herói" ao retratar, na metáfora do esgrimista, o esforço do artista em resistir, por meio da arte, ao curso inexorável do tempo soberano. A resistência heróica do poeta se permeia do sentimento de catástrofe (spleen) na descrição do trabalho poético como um duelo no qual o artista grita de horror antes de ser vencido. ${ }^{25}$

Outro ponto de aproximação que Benjamin identifica, para além das divergências, está na posição do conspirador e do poeta quanto à "crença no progresso": Baudelaire a enfrentava com ódio, enquanto Blanqui a enterrava com seu desprezo. Para ambos, o conceito de progresso precisava "ser fundado na idéia de catástrofe, ${ }^{, 26}$ que possibilitava a crítica ao historicismo, aos esquemas espacializados da progressão de um tempo vazio e homogêneo.

A catástrofe está em que as coisas continuem a se desenvolver desse modo, conforme um curso, uma direção, um sentido. A continuidade da história “consiste na permanência do intolerável", cuja expressão maior é a idéia do progresso. ${ }^{27}$ A ilusão moderna está em crer que o passado representa a barbárie, enquanto o futuro significa avanço, ciência, realização e felicidade. É precisamente a crítica, o confronto, que possibilitam interromper tal curso e criar condições para descobrir o evento histórico. Em Baudelaire, o distanciamento crítico e a desconfiança no progresso foram "a condição indispensável para poder dominar Paris em sua poesia". ${ }^{28}$

Para Blanqui, a idéia de progresso como expressão da conquista científica e da realização da felicidade desejada se constituía em ilusão. ${ }^{29} \mathrm{~A}$ noção de progresso se revela como um mito, no sentido que oculta a verdadeira natureza das relações que se instauram na sociedade moderna: dá a impressão do movimento na forma do desenvolvimento técnico para fins humanos, quando o que realmente acontece é a eterna repetição do mesmo, nas estruturas de poder e na repressão, característica de todas as formas de Estado, bem como das diversas formas de prisão (sociais ou psicológicas) que envolvem o indivíduo (que Blanqui conheceu profundamente, a partir de sua própria experiência). O mito esconde a efetiva situação sob uma aparência e subverte no imaginário as relações reais.

25 BENJAMIN, A Paris do segundo império em Baudelaire, p. 92-93.

26 BENJAMIN, GS., V-I, p. 592. BENJAMIN, Parque central, frag. 35, p. 145.

27 HABERMAS, J. Crítica conscientizante ou salvadora - a atualidade de Walter Benjamin. In: Sociologia (coletânea). São Paulo: Ática, 1980, p. 179.

28 BENJAMIN, Parque central, frag. 35, p. 146.

29 BENJAMIN, GS., I-3, p. 1153. 
As anotações de Benjamin sobre Blanqui anunciam a teoria da história que se concretiza nas Teses, nas quais ecoa a força da classe oprimida como "classe vingadora que, em nome de gerações de vencidos, leva até o fim a obra de libertação". ${ }^{30}$ A leitura de Blanqui permitiu a Benjamin criticar os pressupostos do marxismo implícitos na idéia de revolução permeada pela noção de progresso e abrir caminhos para se repensar o movimento revolucionário como um processo de liberação de todas as aspirações libertárias do passado, numa concepção que se aproxima muito mais da idéia de redenção que da noção de totalidade, que Marx herdou de Hegel e não conseguiu superar.

A história constrói-se no instante presente, tanto em direção ao passado quanto em direção ao futuro, num trabalho em que memória e expectativa de realização se entrecruzam e se renovam. É desse modo que o novo pode nascer das possibilidades infinitas que nos coloca a tradição. A arte se põe como o campo privilegiado em que o antigo e o novo se misturam e interagem e aflora a possibilidade de renovação. 


\section{Referências}

ALTER, R. Anjos necessários: tradição e modernidade em Kafka, Benjamin e Scholem. Rio de Janeiro : Imago, 1993.

BAUDELAIRE, C. O Spleen de Paris. Rio de Janeiro: Imago, 1995. . As Flores do Mal. Rio de Janeiro: Nova Fronteira, 1985, (ed. bilíngüe).

BLANQUI, L. A. Del'Eternità attraverso gli astri. Roma : Theoria, 1983.

BENJAMIN, W. Obras Escolhidas I: Magia e técnica, arte e política. São Paulo: Brasiliense, 1985. . Obras Escolhidas II: Rua de Mão Única. São Paulo : Brasiliense, 1987. . Obras Escolhidas III: Charles Baudelaire - um lírico no auge do capitalismo. São Paulo: Brasiliense, 1989. . Origem do Drama Barroco Alemão. São Paulo: Brasiliense, 1985. . Benjamin (coletânea - Grandes Cientistas Sociais). São Paulo: Ática, 1985. . A criança, o brinquedo, a educação. São Paulo: Summus, 1984.

. Gesammelte Schriften I, 1, 2 und 3 (Abhandlungen). Frankfurt: a.M. : Suhrkamp Verlag, 1997.

. Gesammelte Schriften V, 1 und 2 (Das Passagen-Werk). Frankfurt: a.M. Suhrkamp Verlag, 1991. . Sul concetto di sotria. Torino: Einaudi, 1997. . Briefe I e II. Frankfurt: a.M.: Suhrkamp Verlag, 1971.

HABERMAS, J. Crítica conscientizante ou salvadora - a atualidade de Walter Benjamin. In:___ Sociologia. São Paulo : Ática, 1980. (Coletânea).

MARX, K. Manifesto do Partido Comunista. Rio de Janeiro: Zahar, 1978.

VV. A.A. O Socialismo antes de Marx. Amadora, Portugal: Fronteira, 1976. 